\title{
O “MERCADO DA MORTE” MEXICANO DURANTE A PANDEMIA DA COVID-19 SOB A PERSPECTIVA DO DIREITO, DA ÉTICA E DA MORAL
}

\author{
THE MEXICAN "MARKET OF DEATH” DURING THE PAN-DEMIC OF COVID-19 UNDER \\ THE PERSPECTIVE OF LAW, ETHICS AND MORALE
}

Flávio Tupinambá Cruz de Souza

Universidade Federal de Roraima, Boa Vista, RR, Brasil. E-mail: flavio-tupirr@hotmail.com

\author{
Francisco Artemizio Silva Freitas
}

Universidade Federal de Roraima, Boa Vista, RR, Brasil. E-mail: guerra4646@hotmail.com

\section{Wellingson Cavalcanti de Almeida}

Universidade Federal de Roraima, Boa Vista, RR, Brasil. E-mail: wellingalm@hotmail.com

\section{Douglas Verbicaro Soares}

Universidade Federal de Roraima, Boa Vista, RR, Brasil. E-mail: douglas_verbicaro@yahoo.com.br

DOI: https://doi.org/10.46550/amormundi.v2i5.112

Recebido em: 12.07.2021

Aceito em: 05.09.2021

\begin{abstract}
Resumo: O agravamento da pandemia de Covid-19 no México, logo no início de 2021, fez crescer a demanda por oxigênio e insumos na capital. A urgência por esses itens básicos decorreu do aumento da taxa de ocupação dos hospitais públicos e privados, ocasionando o desabastecimento e aparecimento de vendedores clandestinos ofertando os produtos a preços exorbitantes. Com efeito, em tempos de crise, é normal que as dimensões mais frágeis do ser humano sejam afetadas, porém, até que ponto a escassez de recursos e a luta pela sobrevivência podem influenciar no senso de justiça, ética e moral de pessoas que se encontram em situação extrema de necessidade e vulnerabilidade? A partir dos fatos apresentados, o objetivo desse trabalho é realizar uma análise crítica-jurídica e multidisciplinar sobre as condutas dos agentes - governo, empresas fornecedoras de oxigênio e vendedores clandestinos - no "Mercado da Morte" mexicano, com ênfase na ética, moral, assim como no direito comparado. Para tanto, será usado o método de pesquisa qualitativa e quantitativa, pesquisa bibliográfica e exploratória de dados de fontes abertas. Por certo, ao final deste trabalho, restará claro que a crise provocada pelo novo coronavírus tem sido fator preponderante na determinação de comportamentos e tomada de decisões contrárias ao direito, à ética e à moral.
\end{abstract}

Palavras-chave: Crise sanitária. Falta de oxigênio. Preços abusivos. Senso de justiça. Postura ética. 
Abstract: The worsening Covid-19 pandemic in Mexico in early 2021 has increased demand for oxygen and insumin the capital. The urgency for these basic items resulted from the increase in the occupancy rate of public and private hospitals, causing the thinning and appearance of illegal sellers offering the products at exorbitant prices In fact, in times of crisis, it is normal that the weaker dimensions of the human being are affected, however, to what extent the scarcity of resources and the struggle for survival can influence the sense of justice, ethics and morals of people who are in an extreme situation of need and vulnerability? Based on the facts presented, the objective of this work is to perform a critical-legal and multidisciplinary analysis of the conduct of agents - government, oxygen supplier companies and clandestine sellers - in the Mexican "Death Market", with emphasis on ethics, morals, as well as comparative law. For this, the method of qualitative and quantitative research, bibliographic and exploratory research of data from open sources will be used. Certainly, at the end of this work, it will be clear that the crisis caused by the new coronavirus has been a major factor in determining behaviors and making decisions contrary to law, ethics and morality.

Keywords: Health crisis. Lack of oxygen. Abusive prices. Sense of justice. Ethical posture.

\section{Introduçáo}

Figura 1: Juan Carlos Hernández com tanques de oxigênio vazios fora de um provedor privado de oxigênio não certificado na Cidade do México.

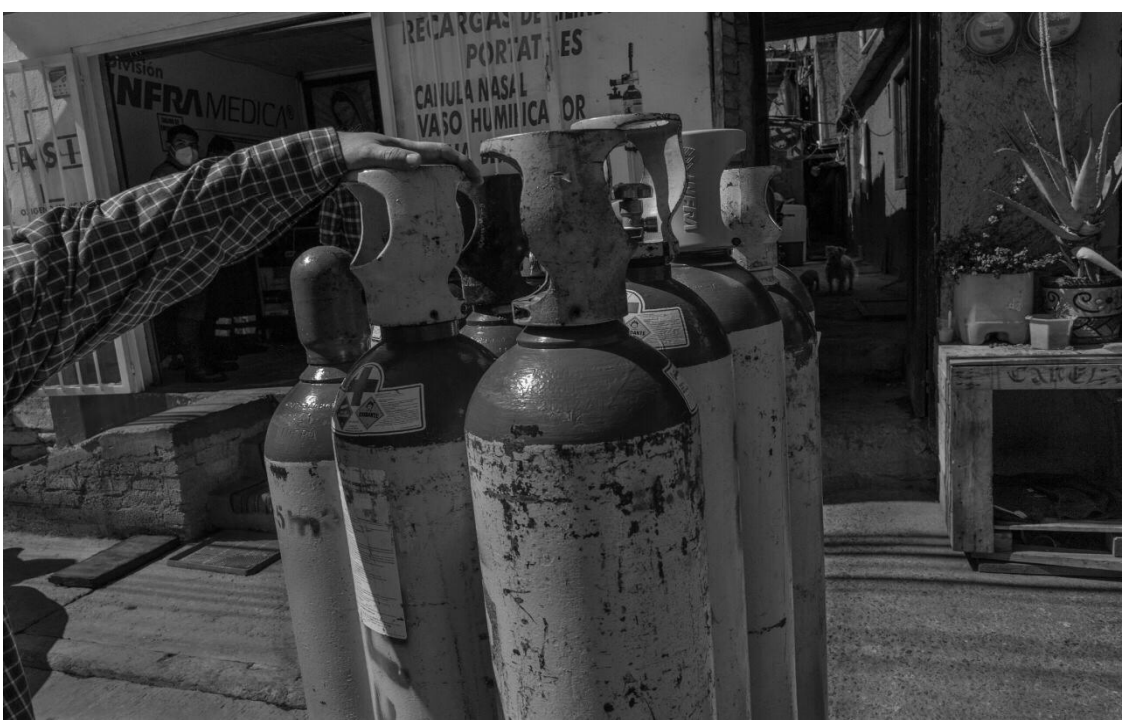

Fonte: The New York Times (KITTROEFF; LOPEZ, 2021).

Se você não tiver dinheiro, pode perder um membro da sua família

Fonte: The New York Times (KITTROEFF; LOPEZ, 2021).

$\mathrm{O}$ início do ano de 2021 não foi um dos melhores para o México. Porquanto, com o agravamento da pandemia de Covid-19, o país vem enfrentando enormes dificuldades, particularmente no que se refere à superlotação dos hospitais, escassez de insumos para a saúde e aumento exacerbado dos preços de cilindros de oxigênio. À vista disso, contabilizase que o número de óbitos naquele país alcançou a marca de 30.000 mortes somente no mês de janeiro de 2021 (KITTROEFF; LOPEZ, 2021). 
O motivo do aumento no número de mortes no México decorre, principalmente, da escassez de cilindros de oxigênio para uso particular, uma vez que a grande maioria dos pacientes acometidos pela Covid-19, por desconfiança, não procuram mais o sistema de saúde mexicano, o que gera a grande demanda por tanques de oxigênio de forma privada, na esperança de ajudar familiares ou amigos que necessitam com urgência desse recurso (KITTROEFF; LOPEZ, 2021).

Por conseguinte, em virtude do aumento dos casos de Covid-19 associada à escassez de oxigênio que o México vem enfrentando, Kittroeff (2021) aponta que nas três primeiras semanas do mês de janeiro de 2021 a demanda por oxigênio doméstico aumentou 700\% no país inteiro. Diante disso, os preços do supracitado insumo triplicaram e diversos vendedores clandestinos surgiram de todos os lados.

Por consequência, surge o que veio a ser denominado de "Mercado da Morte" mexicano, no qual, de um lado, estão pessoas que buscam incesantemente por tanques de oxigênio movidas pelo desespero, estresse e angústia e, de outro lado, encontram-se vendedores clandestinos e empresas, impulsionados pela oportunidade de ganhar dinheiro. Com isso, emerge o seguinte questionamento: até que ponto a escassez de recursos pode influenciar o senso de justiça e ética no contexto da pandemia de Covid-19?

Diante dessa indagação, o presente estudo apresenta uma análise crítica-jurídica e multidisciplinar sobre as condutas dos agentes (governo, empresas fornecedoras de oxigênio e vendedores clandestinos) no "Mercado da Morte" mexicano (criado pelo agravamento da pandemia da Covid-19), com ênfase na ética, moral, bem como no direito comparado, enfatizando o debate crítico-jurídico e multidiciplinar.

Para alcançar esse objetivo, utilizou-se do método de pesquisa qualitativa, bem como pesquisa bibliográfica, jurisprudências, artigos e dados coletados em fontes abertas. Inicialmente, será feita uma breve contextualização sobre a pandemia da Covid-19 no México e o recente agravamento que culminou no chamado "Mercado da Morte". Em seguida, serão apresentados conceitos doutrinários acerca da ética e da moral, com fulcro no Direito comparado, visando arrazoar sobre as condutas dos agentes no "Mercado da Morte" mexicano e a similitude do caso com os fatos que ocorrram na cidade de Manaus, no Amazonas.

Por fim, discorrer-se-á em breves consideraçôes finais acerca de como a ética, a moral e o direito estáo relacionados à conduta dos agentes ora analisados no contexto da pandemia de Covid-19 no México, sobretudo em relação aos aspectos negativos gerados por atitudes negacionistas, irresponsáveis e egoístas que geram colapsos nos hospitais e escassez de recursos destinados à saúde.

\section{Contextualizaçáo histórica do problema}

Primeiramente, impende destacar que a humanidade vivencia uma crise sanitária sem precedentes, a qual foi declarada pela Organização Mundial da Saúde em 11/03/2020 como pandemia da Covid-19 (ONU, 2020). No México, o então presidente Andrés Manuel López Obrador, eleito para o mandato de 2018-2024, teve que traçar uma estratégia de saúde pública para o enfrentamento da Covid-19, visando amenizar os impactos que a pandemia traria a sua nação (RENTERIA; GAULT, 2021). 
Todavia, em janeiro de 2021 (quase um ano após a declaração da OMS), a pandemia da Covid-19 evidenciou a ineficácia da estratégia de saúde montada pelo governo mexicano, apontando características como: negacionismo ao conhecimento científico, desinteresse na busca de informaçôes para o combate à pandemia, superlotação de hospitais, ausência de insumos para a saúde e grande escassez de oxigênio (RENTERIA; GAULT, 2021).

Nesse sentido, a microbióloga mexicana Laurie Ann Ximénez-Fyvie, autora do livro "Danos irreparáveis: a gestão criminosa da pandemia no México", doutora em Ciências Médicas pela Universidade de Harvard e chefe do laboratório de Genética Molecular da Faculdade de Odontologia da Universidade Nacional Autônoma do México, expóe em sua obra que, no México, até sabiam o que deveria ser feito para evitar o alastramento do coronavírus, porém decidiram não fazer (DÍAZ, 2021).

Nesse diapasão, a aludida autora argumenta que o subsecretário de saúde do governo mexicano, Hugo López-Gatell, utilizou critérios políticos ao invés de critérios científicos no comabate a pandemia da Covid-19 (DÍAZ, 2021). Além disso, a literata tece críticas ao governo mexicano, afirmando que:

[...] no México, nem se reconhece que algo ruim está acontecendo, ou seja, eles sempre insistem que a pandemia já está sob controle e que estamos saindo dela. Náo há nenhuma indicação aqui de que se pretende mudar ou melhorar sua estratégia (DÍAZ, 2021).

Figura 2: O México soma mais de 184 mil mortes e mais de dois milhôes de casos de Covid-19, de acordo com o relatório oficial do governo.

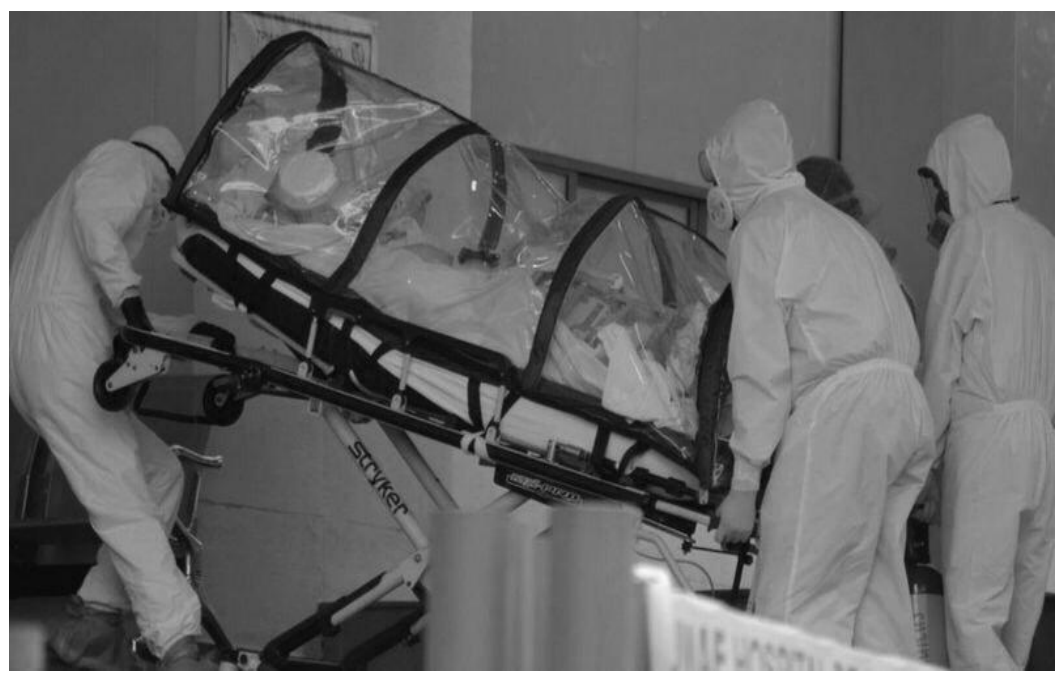

Fonte: BBC News (DÍAZ, 2021).

Continuando, a cientista aduz que é necessário que autoridades públicas sejam responsabilizadas pelo fracasso no combate à pandemia da Covid-19: "Alguém teria que ser responsabilizado. O que aconteceu no México com a pandemia é um verdadeiro crime. Mas, o que quer que façam, nada vai ressuscitar os mortos [...]” (DÍAZ, 2021).

Nesse contexto de fracasso, destacam-se também os dados publicados pela Universidade Johns Hopkins acerca do número de óbitos que o México atingiu em 28/01/2021, qual seja, 155.145 mortes por Covid-19 desde o início da pandemia. Por conseguinte, em janeiro de 2021, o México tornou-se o $3^{\circ}$ país com mais mortes por Covid-19, estando atrás somente do Brasil $\left(2^{\circ}\right)$ e dos Estados Unidos da América $\left(1^{\circ}\right)$ (JOHNS HOPKINS UNIVERSITY \& 
MEDICINE, 2021).

Nesta toada, a capital mexicana (Cidade do México), em janeiro de 2021, sofreu grande impacto da pandemia da Covid-19, com hospitais lotados e falta de oxigênio para os pacientes. Consequentemente, grande parte da população mexicana recorreu ao tratamento em casa e, para a aquisição de cilindros de oxigênio, as pessoas procuravam, por óbvio, o mercado clandestino, mesmo que para isso tivessem que se endividar, impulsionadas pela necessidade, aflição, desespero e angústia (VARELA, 2021).

Como corolário, surge o denomidado "Mercado da Morte" mexicano. Nesse cenário funesto, de um lado há a figura de um governo despreocupado e desacreditado pela população, de outro, o mercado fornecedor de oxigênio e os vendedores clandestinos oferecendo o produto a preços exorbitantes. Sem dúvida, uma das áreas mais afetadas no ser humano em momentos de grande crise e escassez é seu senso de ética e moral. Daí, levanta-se o questionamento: até que ponto a escassez de insumos e recursos pode atingir o senso de justiça e ética dos seres humanos no contexto da pandemia da Covid-19?

\section{A perspectiva do direito, da ética e da moral sobre o tema}

De certo, o advento do novo coronavírus sobre o mundo, além dos males à saúde, trouxe à tona uma enorme quantidade de reflexóes no campo do direito, da ética e da moral. Portanto, antes de mais nada, impende destacar a acepção conceitual etimológica desses termos consoante os entendimentos doutrinários mais abalizados e, em seguida, relacioná-los à situaçáo pandêmica vivenciada.

Destarte, o Direito tem origem no latim directum, derivada do verbo dirigere, que significa "ordenar". Etimologicamente falando, a palavra direito significa "aquilo que é reto, que está em harmonia com a justiça" (RODRIGUES, 2018, p. 2). "O direito é a lei e ordem, isto é, um conjunto de regras obrigatórias que garante a convivência social graças ao estabelecimento de limites à ação de cada um de seus membros"(REALE, 2000, p. 1).

Por seu turno, a ética, nas palavras de William Gustavo Rodrigues, relaciona-se com dois termos gregos: éthos e areté. "Éthos, segundo a sua origem grega, pode ser entendida como "costume", "uso" e "hábito", mas também pode ser compreendida como caráter, temperamento, índole e maneira de uma pessoa ser" (RODRIGUES, 2018, p. 1). Já areté "significa mérito ou qualidade que algum indivíduo tem de mais excelente ou as suas virtudes: corpo, alma e inteligência” (RODRIGUES, 2018, p. 1).

Rodrigues (2018) aduz que Areté foi traduzida para o latim como virtus (virtude) e encontra relação com outra palavra do latim, morale (moral), com aplicação à conduta ou referente aos costume. Por sua parte, moral seria "o agrupamento de normas e regras que regem a conduta do indivíduo em sociedade e em um grupo. As regras são adquiridas por meio de cultura, costumes, tradição, educação e até mesmo do cotidiano" (RODRIGUES, 2018, p. 11).

Já Pequeno et al. (2008) entende que ética e moral são palavras que teriam o mesmo sentido, dizendo respeito à maneira como os indivíduos agem em relaçáo ao outro no espaço em que vivem. Mesmo acreditando nessa união de significados, aduz o ilustre escritor que alguns filósofos defendem a diferença entre ética e moral, sendo a ética responsável por fornecer a compreensão da moralidade do sujeito, ao passo que a moral seria a conduta, o agir de cada um 
(PEQUENO et al., 2008).

Destaca-se assim, pois, que a ética está intrinsecamente ligada à moral e ao direito, no sentido de que têm uma finalidade semelhante, qual seja, nortear o indivíduo para uma vida em sociedade, onde o respeito às leis, regras e costumes, é essencial para sua sobrevivência, dessa forma, evitando sofrer qualquer tipo de coerção, seja penal, civil ou moral.

A par dos conceitos ora apresentados, prima facie, não seria difícil perceber, a partir dos fatos resultantes do chamado "Mercado da Morte" mexicano, que os diversos agentes envolvidos naquele contexto - governo, empresas fornecedoras de oxigênio e vededores clandestinos desrespeitaram preceitos legais, éticos e morais do consenso social estabelecido naquela sociedade.

A começar pelo governo, as críticas dos diversos setores da sociedade mexicana mostram os mais variados cenários que afligem o Estado em decorrência das mortes causadas pela falta de atendimento adequado de pessoas infectadas com a Covid-19. Laurie Ann Ximénez-Fyvie qualificou a gestão governamental mexicana na pandemia como criminosa, pois o governo sabia o que fazer para conter o avanço da doença, porém não o fez por questóes ideológicas e políticas (DÍAZ, 2021).

Amanda Péchy diz que entre as principais causas da elevada taxa de mortalidade no México está a disseminação de desinformação, inclusive pelo próprio presidente Andrés Manuel López Obrador, o qual já relativizou diversas vezes a eficácia das máscaras na prevenção dos contágios, além de ignorar medidas de distanciamento social (PECHY, 2021). Com efeito, a postura ética de um Estado que leva a sério suas políticas de fomento à saúde pública passa, necessariamente, pelo senso de responsabilidade, planejamento no gerenciamento da coisa pública e cuidado para com seus governados.

Outrossim, no campo do direito, é de bom alvitre examinar a conduta do governo mexicano sob a luz do direito das gentes. É consabido que "as normas internacionais de direitos humanos garantem a todos o direito à saúde e exigem que governantes adotem medidas para coibir ameaças à saúde pública e a prestarem assistência médica àqueles que dela necessitam" (HUMAN RIGHTS WATCH, 2020). Contudo, essas normas também reconhecem que em momentos de graves ameaças à saúde humana, como a crise de Covid-19, determinados direitos podem vir a sofrer restriçóes sem, todavia, ferir a dignidade da pessoa humana.

Nessa esteira, o direito à saúde está intrinsecamente relacionado a outros direitos, destacados na Declaração Universal dos Direitos Humanos, quais sejam: os direitos à alimentação, trabalho, dignidade humana, vida, igualdade, etc (ONU, 1948). Esses e outros direitos norteiam elementos integrais do direito à saúde.

Dessa forma, a prudência alvitra que não podem ocorrer a ausência de açóes e medidas dos gestores públicos para gerar respostas adequadas e oportunas a fenômenos como as pandemias. Portanto, é necessária a implementação de políticas públicas eficientes, adequadas e oportunas que possibilitem enfrentar situaçóes de urgência para evitar catástrofes sociais.

Destaca-se que a situação deficiente na saúde pública do México, a qual não foi oportunizado o atendimento médico às pessoas infectadas com a Covid-19, por falta de leitos, bem como as mortes causadas pela escassez de insumos (VARELA, 2021), demonstra a necessidade de implementação de mecanismos de natureza jurídica para fazer frente à pandemia. Portanto, um desses mecanismos é a tutela ao direito à saúde, que goza de especial posição topográfica no 
artigo $4^{\circ}$ da constituição mexicana, in verbis:

Toda pessoa tem direito à proteção da saúde. A Lei definirá as bases e modalidades de acesso aos serviços de saúde e estabelecerá a anuência da Federação e dos entes federativos em matéria de saúde geral, de acordo com o disposto no inciso XVI do artigo 73 desta Constituição. A Lei definirá um sistema de saúde para o bem-estar, de forma a garantir a extensão progressiva, quantitativa e qualitativa dos serviços de saúde para o atendimento integral e gratuito às pessoas que não possuem seguridade social. Parágrafo adicionado DOF 02-03-1983. DOF remodelado 08- 05-2020 (MÉXICO, 1917).

De outro lado, nesse quadro de instabilidade do sistema de saúde mexicano, as empresas que vendem oxigênio rapidamente perceberam uma possibilidade de aumentarem os preços do insumo, uma vez que a demanda do governo e das pessoas era crescente. No final de 2020, várias empresas fornecedoras de oxigênio foram investigadas pela Comissão Federal de Concorrência Econômica, órgão antimonopólio do país, por supostas práticas abusivas, o que culminou em 16 estabelecimentos fechados por venderem o oxigênio a preços inflacionados (VARELA, 2021).

Por óbvio, a oferta e a demanda são lógicas de mercado que regulam a economia mundialmente. Contudo, em um cenário pandêmico, onde muitas empresas tiveram que fechar suas portas devido às exigências do momento, é no mínimo injusto, vil, antiético e imoral o fato de que algumas empresas que consigam se manter abertas aumentem exorbitantemente os preços. Em verdade, nessas práticas percebe-se a quebra de fundamentos que norteiam a ética empresarial, as quais se reproduzem não apenas na busca pelo lucro, mas também por uma responsabilidade social e senso de solidariedade.

Assinala-se, por último, a conduta dos vendedores clandestinos de oxigênios e seus insumos. A escassez e o aumento dos preços fez crescer a ambição de algumas pessoas, que passaram a vender o produto a preços bem acima do normal (KITTROEFF; LOPEZ, 2021). Observa-se então, com clareza, que para alguns seres humanos, este instante de grave crise que vivenciamos se torna o ensejo ideal para tirar proveito de outras pessoas, sem nenhum escrúpulo pela dor e sofrimento alheio. De certo, uma conduta egoísta, repulsiva e abjeta do ponto de vista do direito e da moral.

O cenário favorável de combate ao "Mercado da Morte" mexicano, desperta a importância do senso de moralidade e das boas condutas éticas na sociedade, seja durante a gestão de recursos públicos, seja nas práticas econômicas de entes privados. Demais disso, portanto, é de opinião unívoca a necessária garantia de direitos humanos no enfrentamento à pandemia da Covid-19 como concretizaçáo de um direito ético e moral fomentador da justiça e equidade, principalmente para os mais vulneráveis.

\section{A escassez de recursos e o Direito comparado}

Como já mencionado anteriormente, a pandemia da Covid-19 é um fato novo enfrentado por todo o mundo. Dessa maneira, os problemas econômicos-sociais, especialmente os provocados pela má alocação de recursos, colapso na saúde pública e falta de insumos para o combate e tratamento do vírus, ocorrem em vários países, principalmente em naçóes emergentes localizadas geograficamente no hemisfério sul, como é o caso do Brasil.

Nesse sentido, em meados de janeiro de 2021, foi noticiado pela mídia que mortes 
estavam acontecendo em Manaus-AM por falta de oxigênio medicinal (SCHIMIDT, 2021). Essas mortes estavam relacionadas a pacientes diagnosticados com o vírus causado pela pandemia da Covid-19.

A deficiência no atendimento pela falta de leitos e escassez de recursos para o tratamento e combate ao vírus, obrigou a remoção de muitos doentes para outros Estados. O fato chocou o Brasil e diversos países, principalmente quando veio à público a notícia de pessoas morrendo numa regiáo considerada o "pulmáo do mundo".

Os médicos alegavam que a crise do oxigênio aconteceu pela falta de coordenação e decisões erradas de autoridades, às quais não deram a devida importância ao perigo da pandemia e a nova cepa do vírus (SCHIMIDT, 2021). O governo do Amazonas, prevendo um colapso no sistema de saúde, editou em 23 de dezembro de 2020, um Decreto determinando o fechamento do comércio não essencial e, a partir do dia 26 do mesmo mês, proibiu eventos comemorativos (AMAZONAS, 2020). Tal medida provocou protestos da população amazonense, principalmente no que se refere à classe de empresários e comerciantes (CORREIO BRAZILIENSE, 2020).

Figura 3: Trabalhadores do comércio durante manifestação contra o decreto.

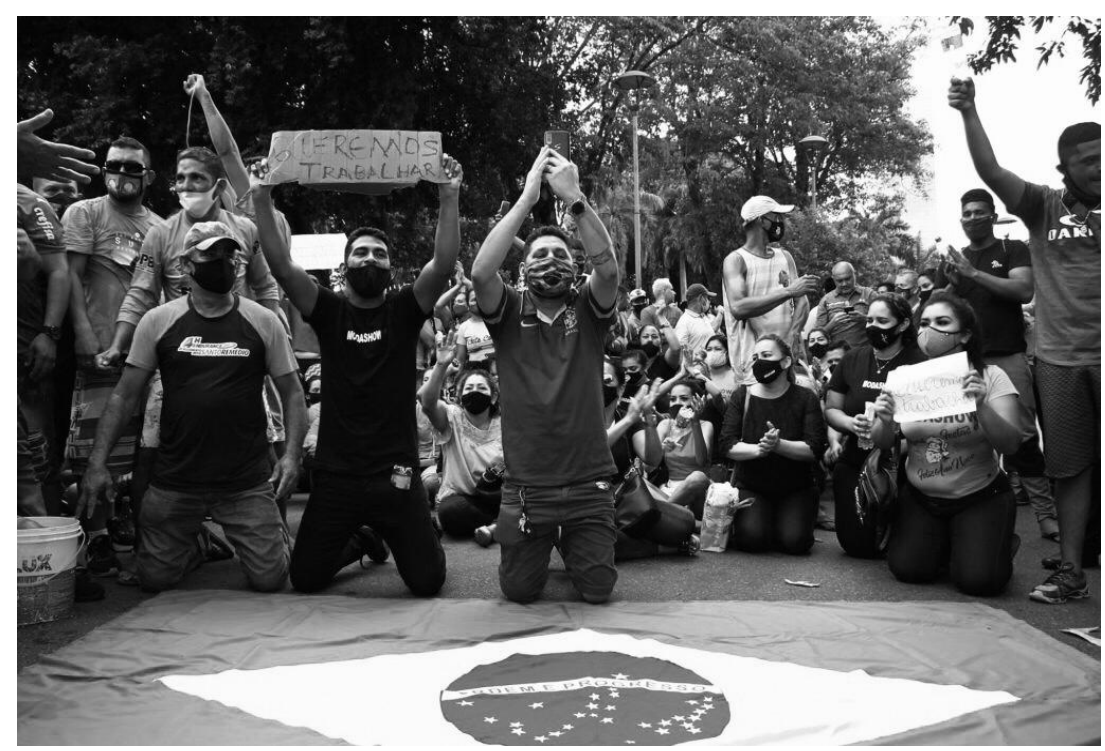

Fonte: Amazonia Real (RIBEIRO, Edda; BRASIL, Kátia, 2020).

Diante desses fatos ocorridos em Manaus, seria possível identificar condutas que, porventura, tenham se furtado aos ditames do direito, da ética e da moral? Levando-se em consideraçáo que as mortes ocorridas naquele momento provavelmente ocorreram pelo descaso ou pela não observaçáo das medidas de precauçáo necessárias para o combate ao vírus, o que praticamente colapsou o sistema de saúde amazonense, prima facie, se estabelece uma linha comparativa que se assemelha às faltas e desvios ocorridos no México.

Nesse diapasão, no tocante ao direito, salienta-se que o ordenamento jurídico brasileirio protege os direitos humanos, encartados na Declaração Universal de Direitos Humanos (DUDH) e na Constituição Federal de 1988 (CF/88). Dessa forma, é importante ressaltar o que dispóe o art. 196 da $\mathrm{CF} / 88$ :

A saúde é direito de todos e dever do Estado, garantido mediante políticas sociais e econômicas que visem à reduçáo do risco de doença e de outros agravos e ao acesso universal e igualitário às ações e serviços para sua promoção, proteção e 
recuperação (BRASIL, 1988).

Para Barreto et al. (2021), o Ministério da Saúde e o governo do Estado do Amazonas acompanharam a aceleração dos casos de Covid-19 em Manaus, mas não tomaram medidas eficazes a tempo, o que culminou nas mortes por falta de oxigênio. Dias depois, essa tragédia se repetiu em outras cidades do interior do Amazonas.

Com efeito, quando o gestor público se afasta do cumprimento do direito, sua conduta não é legítima, posto que se furta às exigências da lei. Porém, não basta cumprir a lei, pois uma conduta legítima deve acima de tudo se pautar na probidade, só então o que é legal estará se pautando pelo que é moral, honesto e conveniente ao interesse público (MEIRELES, 2016).

Cabe ressaltar, entretanto, que não basta apenas uma atuação honesta, proba e escorreita do Estado para enfrentar a pandemia, sendo extremamente importante também o empenho de toda população. A pandemia da Covid-19 traz à tona diferentes aspectos de ética, o que envolve a ação de todos os indivíduos da sociedade (GOLDENBERG, 2020). Deveras, princípios éticos e morais são comprometidos quando comerciantes aumentam os preços dos insumos de saúde, criminosos praticam roubo de cilindros de oxigênio e quando gestores deixam de aplicar os recursos necessários ao tratamento e combate às pandemias.

\section{Consideraçóes finais}

Destarte, o infausto "Mercado da Morte" mexicano, caracterizado pelo aumento no número de mortes decorrentes da escassez de cilindros de oxigênio, revela que o campo da ética e da moral, bem como o senso de justiça, são áreas frágeis na vida do ser humano, especialmente em momentos de crise.

Sem dúvidas, os atores ora analisados neste cenário funesto no México - governo, empresas e vendedores clandestinos de oxigênio/insumos -, deixaram transparecer a imoralidade, a improbidade, a desonestidade, falta de solidariedade, a não eticidade e o pouco senso de justiça em suas condutas para com as outras pessoas.

Entrementes, a situação que ocorreu no Brasil, na cidade de Manaus, guardou estreita similitude com o caso do México, no que diz respeito às causas. Porquanto, em ambos houve um descaso governamental com a vida humana e com a gestão da res pública, por questôes políticas e ideológicas. Isso, por si só, é incondizente com a moral, com a ética e com os princípios da Administração Pública, em especial o da legalidade e moralidade.

Portanto, em virtude dessas consideraçôes a respeito da conduta dos agentes envolvidos nas mortes no México, não restam dúvidas de que a escassez de recursos e a luta pela sobrevivência influenciaram significativamente no senso de justiça, ética e moral daquelas pessoas.

\section{Referências}

AMAZONAS. Decreto no 43.234, de 23 de dezembro de 2020 - Governo do Amazonas publica decreto em cumprimento à decisão judicial que suspende atividades não essenciais. Disponível em: <http://www.amazonas.am.gov.br/content/uploads/2021/01/23-12-2020_poder_executivo. pdf $>$. Acesso em: 28 de mar. 2021. 
BARRETO, Ivana Cristina de Holanda Cunha et al. Colapso na Saúde em Manaus: o fardo de não aderir às medidas não farmacológicas de redução da transmissão da COVID-19. Scientific Electronic Library Online, São Paulo, 2021. Disponível em: <https://preprints.scielo.org/ index.php/scielo/preprint/view/1862/3001>. Acesso em: 27 de mar. 2021.

BRASIL. Constituição da República Federativa do Brasil, 1988. Disponível em: <http://www. planalto.gov.br/ccivil_03/constituicao/ConstituicaoCompilado.htm>. Acesso em: 27 de mar. 2021.

CORREIO BRAZILIENSE. Centenas de pessoas fazem protesto em Manaus contra fechamento do comércio. Pandemia, dez. 2020. Disponível em: <https:/www.correiobraziliense.com.br/ brasil/2020/12/4897050-centenas-de-pessoas-fazem-protesto-em-manaus-contra-fechamentodo-comercio.html>. Acesso em: 28 de mar. 2021.

CREDITPERFORMANCE. A ética em tempos de crise: Entrevista com o Clóvis de Barros Filho. São Paulo, 2015. Disponível em: <https://www.creditperformance.com.br/web/a-etica-emtempos-de-crise-entrevista-com-o-clovis-de-barros-filho/>. Acesso em: 29 de mar. 2021.

DÍAZ, Marcos González. Coronavírus: 'No México, não é que não soubessem o que fazer com a pandemia, é que decidiram não fazer'. In: BBC News, mar. 2021. Disponível em: <https://www. bbc.com/portuguese/internacional-56257413>. Acesso em: 15 de mar. 2021.

GOLDENGERG, Samuel. Seminários Integrados (COVID-19) - Ética em tempos de pandemia, 2020. Disponível em: <http:// https://portal.fiocruz.br/video/seminariosintegrados-covid-19-etica-em-tempos-de-pandemia>. Acesso em: 27 de mar. 2021.

HUMAN RIGHTS WATCH. Dimensóes de direitos humanos na resposta à COVID-19. Disponível em: <https://www.hrw.org/pt/news/2020/03/23/339654>. Acesso em: 27 de mar. 2021.

JOHNS HOPKINS UNIVERSITY \& MEDICINE. Painel COVID-19 do Centro de Ciência e Engenharia de Sistemas (CSSE) da Universidade Johns Hopkins (JHU), 2021. Disponível em: <https://coronavirus.jhu.edu/map.html>. Acesso em: 15 de mar. 2021.

KITTROEFF, Natalie; LOPEZ, Oscar. 'El mercado de la muerte': el desabasto oxígeno causa muertes en México. In: The New York Times, fev. 2021. Disponível em: <https://www.nytimes. $\mathrm{com} / \mathrm{es} / 2021 / 02 / 09 /$ espanol/mexico-tanque-oxigeno.html?smid=wa-share $>$. Acesso em: $14 \mathrm{de}$ mar. 2021.

MEIRELLES, Hely Lopes. Direito administrativo brasileiro. 42a . Ed. São Paulo: Malheiros, 2016.

MÉXICO. Constitución Política de Los Estados Unidos Mexicanos, 1917. Disponível em: $<$ http://www.diputados.gob.mx/LeyesBiblio/pdf_mov/Constitucion_Politica.pdf >. Acesso em: 27 de mar. 2021.

ORGANIZAÇÃO DAS NAÇÓES UNIDAS (ONU). Organização Mundial da Saúde declara novo coronavirus uma pandemia, mar. 2020. Disponível em: <https://news.un.org/pt/ story/2020/03/1706881>. Acesso em: 14 de mar. 2021.

ORGANIZAÇÃO DAS NAÇÓES UNIDAS (ONU). Declaração Universal dos Direitos Humanos, 1948. Disponível em: <http://www.onu-brasil.org.br/documentos_direitoshumanos. 
php>. Acesso em: 27 de mar. 2021.

PECHY, Amanda. Como o México virou o país com a maior mortalidade por Covid-19 do mundo. 2021. Disponível em: <https://veja.abril.com.br/mundo/como-o-mexico-virou-o-paiscom-a-maior-mortalidade-por-covid-19-do-mundo/>. Acesso em: 02 de abr. 2021.

PEQUENO, Marconi. Ética, Educaçáo e Cidadania. In: ZENAIDE, Maria de Nazaré Tavares; GUERRA, Lúcia de Fátima Ferreira; NÁDER, Alexandre Antonio Gili. Direitos Humanos: Capacitação de Educadores. Joáo Pessoa: Editora Universitária da UFPB, 2008, p. $41-48$.

REALE, Miguel. Liçôes preliminares de direito. 25. ed. Saraiva. São Paulo, 2000.

RENTERIA, Cesar; GAULT, David Arellano. Como um governo populista interpreta e enfrenta uma crise na área de saúde? Evidências provenientes da resposta populista mexicana à COVID-19. In: Revista de Administração Pública - Centro de investigação e docência econômica, Cidade do México, México, v. 55, no 1, 2021.

RIBEIRO, Edda; BRASIL, Kátia. Pandemia: Comerciantes protestam contra decreto e gritam "Fora Wilson Lima", em Manaus. Amazonia Real, dez. 2020. Disponível em: <https:// amazoniareal.com.br/pandemia-comerciantes-protestam-contra-decreto-e-gritam-fora-wilsonlima-em-manaus/>. Acesso em: 28 de mar. 2021.

RINCÓN, Francisco de Jesús Cepeda; GONZÁLEZ, Guadalupe Friné Lucho. La Pandemia de Covid-19 y Los Derechos Humanos en México. In: Revista Direitos Sociais e Políticas Públicas - UNIFAFIBE, v.8, p. 488-514, 2020.

RODRIGUES, William Gustavo, et al. Ética geral e jurídica. Porto Alegre: Sagah, 2018.

SCHIMIDT, Steffanie. Morrer sem oxigênio em Manaus, a tragédia que escancara a negligência politica na pandemia. In: El País, jan. 2021. Disponível em: <https://brasil.elpais.com/ brasil/2021-01-15/morrer-sem-oxigenio-em-uma-maca-em-manaus-a-tragedia-que-escancaraa-negligencia-politica-na-pandemia.html>. Acesso em: 28 de mar. 2021.

VARELA, Micaela. Com hospitais lotados, busca por oxigênio dispara na Cidade do México. In: El País, jan. 2021. Disponível em: <https://brasil.elpais.com/internacional/2021-01-14/comhospitais-lotados-busca-por-oxigenio-dispara-na-cidade-do-mexico.html>. Acesso em: 15 de mar. 2021. 